\title{
Camiñando nas marxes con Xohán Casal: espiritualidade popular e expresión literaria ${ }^{1}$
}

\section{Walking in the Margins with Xohán Casal: Popular Spirituality and Literary Expression}

\author{
María Teresa Bermúdez Montes² \\ Universidade de Vigo \\ bermudezteresa@uvigo.gal
}

Recibido: octubre 2020. Aceptado: enero 2021

\begin{abstract}
Resumo: Este traballo presenta un achegamento á figura do escritor galego Xohán Casal (1935-1960) a partir dos seus escritos persoais, que proporcionan novas claves para a súa caracterización. Mediante o estudo dos materiais depositados na Real Academia Galega (Fondo Xohán Casal), poñeranse de manifesto tanto a súa ideoloxía como o seu posicionamento estético e vital, no que ten unha relevancia capital a espiritualidade e o compromiso co popular. Tamén se revelarán as influencias de autores como Eduardo Pondal, cuxa cosmovisión deixou fonda pegada no pensamento de Casal, xunto con Castelao e Luís Seoane.
\end{abstract}

Palabras chave: narrativa galega do século XX, Xohán Casal, relixiosidade, Eduardo Pondal

\begin{abstract}
This paper presents an approach to the figure of the Galician writer Xohán Casal (1935-1960), using Casal's personal writings to provide new keys for the analysis of his literary figure and narrative texts. The study of these unpublished materials - preserved as Fondo Xohán Casal in the Real Academia Galega - reveals little known aspects of Casal's ideology, aesthetics and existential position, such as spirituality and commitment to popular culture from Galicia. These new documents show how Casal took Eduardo Pondal (1835-1971) — whose worldview has left a deep mark on Casal's thought—- Alfonso Daniel Rodríguez Castelao (1886-1950) and Luís Seoane (1910-1979) as literary and political models.
\end{abstract}

Keywords: $20^{\text {th }}$ century Galician narrative, Xohán Casal, religion, Eduardo Pondal

\footnotetext{
1 Esta pesquisa foi financiada polo proxecto «Cuerpos en tránsito 2: Diferencia e Indiferencia / Bodies in Transit 2: Difference and Indifference». Ref.: FFI2017-84555-C2-2-P, MINECOFEDER (España).

2 ORCID ID: https://orcid.org/0000-0001-5481-8834.
} 


\section{I.- INTRODUCIÓN. UN ESCRITOR GALEGUISTA NA CORUÑA DA POSGUERRA}

Xohán Casal (1935-1960) publicou postumamente unha única obra en galego, a colección de contos $O$ camiño de abaixo, editada en 1970 polas Ediciós do Castro a partir da selección que Reimundo Patiño e Isaac Díaz Pardo realizaron dos seus orixinais. En 1985 vería a luz unha segunda edición aumentada, na que se sumaron tres novas pezas aos trece relatos inicialmente incluídos.

Malia padecer unha incurable doenza cardíaca que lle limitaba os movementos, Casal conseguiu producir unha obra literaria en galego innovadora e de calidade, na súa meirande parte inédita. Cultivou durante a súa breve traxectoria vital todos os xéneros literarios, inicialmente en castelán e posteriormente en galego, con clara preferencia pola narrativa. No Fondo Xohán Casal do Arquivo da Real Academia Galega consérvanse un total de 120 textos narrativos (62 en castelán e 58 en galego), 26 textos poéticos, 12 textos ensaísticos e 9 textos dramáticos, ademais de debuxos e notas en menor número.

Por outra banda, a avidez lectora e unha gran curiosidade intelectual permitiron a Casal converterse nun bo coñecedor da literatura galega e occidental. Acadou unha moi ampla cultura, coñecemento de diversas literaturas e de idiomas estranxeiros (inglés), ao tempo que seguía estudos na Escuela de Altos Estudios Mercantiles da Coruña (Prieto 1985: 29) e mesmo desenvolvía unha colaboración nunha radio local, como se desprende dos seus textos ${ }^{3}$.

Casal pertencía a unha acomodada familia de tradición socialista e galeguista, polo que tivo acceso á ben dotada biblioteca familiar. No que se refire á literatura galega, o seu coñecemento da tradición literaria do país abrangue a etapa medieval, como mostran as súas referencias á poesía trobadoresca. No Rexurdimento, coñece a obra de Rosalía de Castro (tanto en galego como en castelán) e valora moi positivamente as figuras de Eduardo Pondal e Manuel Curros Enríquez, como revelan diversos escritos dos que nos ocuparemos máis adiante. Xa no século XX, salienta a obra e o compromiso de Antón Villar Pon$t^{4}$, Antonio Noriega Varela e Xohán Vicente Viqueira ${ }^{5}$. Da obra dos galeguistas da xeración Nós, salienta especialmente a Alfonso Rodríguez Castelao - como home de acción por Galicia - e a Ramón Otero Pedrayo, mentres que se mostra moi crítico con Vicente Risco, pola contra. Grazas á lectura de As cruces de

3 Polo que se desprende das súas cartas, o labor na radio era esixente mais tamén gratificante, porque lle permite conseguir uns ingresos. Confesa, así, o seguinte: «O choio da Radio eisixe unha grandísma forza de vountade»; no mesmo escrito, unhas liñas máis arriba, anunciaba: «Vou alugar unha máquina con moita seguridade, o que che di, sen máis verbas, que o chopo da radio vai ben» («Borrador de carta a Reimundo Patiño», 17-1-1958).

4 «Poucos homes tivemos d'aición. Curros, Castelao e outros máis, pro inda son poucos. O que fixo un teñen que facelo todos. É ben certo que Castelao e outros moitos aituaron con toda a forza do seu corazón, máis abonda con botar unha ollada ao cabo dos Evanxeos da Risa Aisoluta do Villar Ponte» («Diario», s/d).

5 Ensayos y poesías. Nós, Pubricacións Galegas e Imprenta, 1930. Casal dedicou moitos esforzos a conseguir un volume, malia o seu prezo elevado. Finalmente, regaloullo Enrique Iglesias no Nadal de 1959 («Borrador de carta a Reimundo Patiño», 7-12-1959). 
pedra na Galiza ${ }^{6}$, de Castelao, Casal dará un paso substancial na súa práctica como escritor. Así, no tránsito entre 1956 e 1957 deixa atrás o castelán como lingua literaria, para comprometerse en exclusiva coa escrita en galego. Como testemuñou Reimundo Patiño, «racha co seu facer en castelán por consideralo nemigo do seu pobo» (1970: 17). Así, a partir de novembro de 1956 producirá fundamentalmente textos literarios en galego. No ronsel de Castelao, destaca especialmente a Luís Seoane como modelo de acción galeguista e de escritor, polo seu compromiso inquebrantable con Galicia. Entre os seus contemporáneos, coñece ben a poesía da Escola da Tebra ${ }^{7}$, con preferencia por Manuel Cuña Novás e Manuel María, e tamén a obra de Xosé Luís Franco Grande.

Fronte ao pesimismo e á angustia que experimentou Casal como ser humano, os libros supuxeron, por unha banda, un camiño de coñecemento e superación na súa faceta de lector e, por outra, unha oportunidade de actuar, isto é, un obxectivo vital a través da práctica da escrita literaria, como veremos máis adiante. A relevancia da proposta de Casal, na súa faceta de escritor, para o desenvolvemento do campo literario galego non é nada desdeñable, mesmo tratándose dun autor periférico tamén no ámbito da resistencia cultural galeguista da época, como destacou Regueira: «[a] pesar (...) da súa limitada circulación, as tomas de posición de Xohán Casal teñen unha innegábel potencialidade na emerxencia dese campo literario» (Regueira 2020: 364).

\section{II.- CONTEXTO HISTÓRICO E CULTURAL. A REARTICULACIÓN DA CULTURA GALEGA NA POSGUERRA}

A sociedade e a cultura galegas viviron anos plúmbeos durante a longa ditadura franquista (1939-1975), réxime totalitario que impuxo un programa dominado pola violencia (censura e represión) e polo desenvolvemento dun programa de «renacionalización» españolizadora (Molina Aparicio 2017: 26).

Con este fin, o franquismo afanouse en pór «en marcha todo un proceso de aculturación para sustituir la cultura popular preexistente por una determinada cultura política de exaltación al caudillo, de identificación con los fascismos europeos y el anticomunismo, la vuelta al Imperio y los valores del catolicismo conservador» (Ramírez-Melgarejo 2014: 555). Tratábase de anular toda posibilidade

${ }^{6}$ O libro fora publicado postumamente pola Editorial Nós, en Bos Aires. Tamén nesta ocasión foi relevante a intervención de Reimundo Patiño, quen obtivera un exemplar dun tío seu proveniente de Bos Aires, volume ao que tivo acceso Casal.

7 A denominación abrangue a produción poética publicada fundamentalmente na década dos cincuenta por poetas mozos, non marcados pola vivencia directa da guerra civil. Entre os autores máis significativos destacan Manuel María (Muiñeiro de brétemas, 1950; Morrendo a cada intre, 1952; Advento, 1954), Manuel Cuña Novás (Fabulario novo, 1952) ou os integrantes de Brais Pinto Alexandre Cribeiro (Acoitelado na espera, 1960) e Bernardino Graña (Poema do home que quixo vivir, 1960). Xosé Luís Franco Grande (Entre o si e o non, 1967) e Avilés de Taramancos (A frauta i o garamelo, 1959), poetas ambos con quen Casal mantivo relación, son encadrados tamén nesta corrente fundamental na poesía galega de posguerra, caracterizada pola expresión poética da soidade e da angustia do eu lírico. 
de disidencia no seo da sociedade e desactivar a posibilidade de desenvolver un pensamento máis alá da ortodoxia oficial nacional-católica. Por outra banda, aplicouse tamén un programa de control ou «domesticación social», dirixido a garantir a durabilidade dese sistema pola construción dun modelo de sociedade constituído por un suxeito sometido e pasivo, para o que Salvador Cayuela (2009 e 2014), desde a socioloxía histórica, propón a categoría de homo patiens. Esta categoría designaría «un amplio sector de los españoles producido por la dictadura» mediante a violencia (censura e represión) e o adoutrinamento ideolóxico, coa «resignación, la despolitización, la desconfianza en la objetividad del Estado y la gestión del bien común, la increencia en la moral pública» como trazos persistentes (Martínez Cavero 2015: 306).

Xa que logo, o réxime proxectaba conformar unha cidadanía submisa, encadrada nos parámetros de pensamento e acción dun estado centralista e nacionalcatólico. No caso da Galicia, como nos de Cataluña e Euskadi, a represión do estado franquista atinxiu ademais os elementos identitarios como a lingua e, por conseguinte, a expresión literaria nela vehiculada. Nese marco, para a intelectualidade que permanecía no país presentábanse dúas opciones, a aceptación ou a resistencia, por canto «incluso en los regímenes de absoluta dominación, donde no hay relación de poder sino de submisión, existen siempre resistencias», como afirma Ramírez-Melgarejo (2015: 557), seguindo a Scott (1990). Así, o adoutrinamento e o control represivo non evitaron o desenvolvemento de espazos paralelos, de reducidos ámbitos de resistencia, que supuxeron un desafío na práctica ao perfil do homo patiens.

\section{a) A resistencia galeguista: o círculo compostelán e o núcleo da Coruña}

$\mathrm{Na}$ cultura galega xurdiron voces inconformistas e insubmisas, continuadoras do galeguismo de preguerra, que se rebelaron contra a ideoloxía imposta asimiladora e, polo tanto, contraria ás denominadas culturas regionales- $\mathrm{e}$ contra as pexas para a utilización escrita e literaria do galego. Neses anos escuros (Franco Grande 1985), o galeguismo movíase na clandestinidade e o mero feito de facer literatura en galego supoñía materializar a disidencia co franquismo.

O núcleo principal da resistencia galeguista reconstruíuse e articulouse en Santiago de Compostela, darredor do proxecto do grupo editorial Galaxia e á calor da vida universitaria compostelana, favorecido polo ambiente creado por unhas minorías concienciadas e militantes (Franco Grande 1985; Regueira 2020). Era ben distinto o ambiente cultural na Coruña onde, como noutras cidades galegas, o galeguismo non estaba tan articulado, como se ten sinalado ${ }^{8}$. O

8 En palabras de Franco Grande: «Anos escuros, verdadeiramente. Neles todo era difícil, e un tiña a sensación de ser un tipo raro. Como a tiña Xohán Casal, perdido na Coruña, onde ninguén o coñecía e onde non coñecía a ninguén, e que aínda querendo ser escritor galego, nin sequera sabía a onde se podía dirixir, nin con quen se relacionar» (Franco Grande 1985: 188). Tamén Xohana Torres se lamentaba da situación en Ferrol, onde residía, en carta a Franco Grande: «Aquí non 
poeta Avilés de Taramancos, membro do círculo de Casal, retrata deste xeito a atmosfera da cidade herculina na época (Avilés de Taramancos 1992: 22):

Certamente o entorno socio-político da Coruña nos anos cincuenta non era doado. Governados militarmente por un musulmán (aínda que para o caso é o mesmo), civilmente por un requeté devaluado, e municipalmente por un delegado permanente do Caudillo —é dicir, un caudillo en pequeno—, controlada a povoación de cotío por ser sede de verán, de pesca e de caza do señor de Meirás, era difícil calquer expresión cultural, e menos política, que non estiver axustada aos programas oficiais do Estado.

O ambiente, xa que logo, era claramente hostil, como testemuñou o propio Casal, para quen «A Cruña é un inferno» («Borrador de carta a Franco Grande», 26-9-1957). Nese marco, a dificultade para a difusión de obra literaria en galego era practicamente insalvable, malia o voluntarismo e o compromiso. Casal lamentábase amargamente da situación: «es malo para el que camina encontrar todas las puertas cerradas, y no sé qué sucede que cuando se enteran de que escribo en gallego, van y me cierran las puertas en las narices» («Carta a Franco Grande», 24-8-1957, en Franco Grande 1985: 96). Ao outro lado do Atlántico, as iniciativas culturais promovidas polos núcleos de exiliados en América, e concretamente en Bos Aires, ofrecían unha oportunidade de publicación que Casal non dubidou en explorar, aínda que sen éxito. En carta á libraría Follas Novas, o escritor confesa a falta de motivación que provoca non ter expectativa de publicación, ao tempo que pide unha oportunidade («Borrador de carta á librería Follas Novas», 15-11-1958):

Coma quera q'eu son escritor —inda mozo — gostaría de mandare a Bos Aires algun escrito meu. Fai caseque un ano que non escribo e a falla de lugares onde pubricar non m'anima ren. ¡Habería un espazo n’unha revista galega pros meus contos? Gostoso voltaría a escribir sabendo que pubricaría de contado. Certamente que non pretendo que se ademitan a priori os meus traballos, non pido remuneración algunha.

En definitiva, a cidade herculina foi o escenario no que Casal desenvolveu a súa actividade literaria e - en menor medida - artística, interactuando cun reducido grupo de amigos que alimentaban reciprocamente as súas inquietudes culturais a base de lecturas e entusiasmo. Malia ter sido tradicionalmente adscrito á Nova Narrativa Galega ${ }^{9}$ — como un dos artífices da renovación da narrativa da década dos cincuenta- e de estar fortemente vinculado coa Escola da

\footnotetext{
é Santiago. Se soubeses o ambiente... Isto é un departamento coas súas consignas, enteiramente cumpridas... Teño unha forza vital. Está ben aniñada. Non hai perigo de perdela, pois» (Xohana Torres, en Franco Grande 1985: 30).

9 A denominada Nova Narrativa Galega engloba un conxunto de autoras e autores mozos cuxas obras narrativas — caracterizadas pola súa innovación temática e formal— foron publicadas entre 1954 e 1971. Entre os principais autores, destacan Gonzalo Rodríguez Mourullo, María Xosé Quezán, Xosé Luís Méndez Ferrín, Camilo Gonsar, Carlos Casares ou Xohana Torres (Bermúdez 2005: 83-90; Regueira 2020).
} 
Tebra, Casal destaca pola súa singularidade. Cabe situalo na «Xeración $d a$ noite», na denominación de Franco Grande $(1985)^{10}$, equivalente á «Xeración das Festas Minervais» na terminoloxía de Méndez Ferrín (1986: 262-263), quen enmarcou a Casal nun núcleo coruñés, diferenciado do núcleo compostelano que se desenvolvía darredor de Ramón Piñeiro ${ }^{11}$.

Formaban parte dese círculo o propio Xohán Casal, xunto con Reimundo Patiño, Avilés de Taramancos, Enrique Iglesias, Eduardo Martínez, Xosé Parga, entre outros (Patiño 1985; Bermúdez 2005). Varios membros deste grupo, segundo testemuñou Avilés de Taramancos (1992: 17-18), declararon o seu compromiso de «adicación ata a morte, folgo a folgo, por unha Galiza Ceibe e popular» e agrupáronse baixo o nome de «Artistas Ceibes», con ánimo de oporse á represión e o silenciamento reinantes.

Así, esa mesma cidade «tomada» polo franquismo foi capaz de «criar anticorpos» nese reducido espazo de resistencia, eses «anticorpos que unha sociedade mutante, corrupta ou gangrenada por influéncias estrañas, necesita para manter a sua autenticidade, e irradiar ainda algo de seu nos demais estamentos da sociedade galega» (Avilés de Taramancos 1992: 22). Claramente a contracorrente, o autor atreveuse a desafiar normas e interditos, escribindo poemas de homenaxe aos asasinados polo réxime, como «Campo da Rata» (Casal 2005: 207-210) ou protagonizando actos de rebeldía en eventos públicos:

Xohán Casal escribiu Campo da Rata a comezos dos anos 50, cando o que dominaba era un silencio mudo e un ambiente cultural desmemoriado, ruín e hostil. Aínda que Casal e Reimundo tiñan a valentía, nese intre heroica, de interromper ás veces os recitais de poesía da escola do «matonismo cursi» que proferían os vates do grupo falanxista Amanecer. O seu xeito de boicot era berrar á fin da peza lírica: « YY ahora una de calamares!» (Rivas 2009: 18)

Nesa conxuntura, Casal esforzouse en romper coa soidade ao establecer unha fecunda correspondencia con escritores galeguistas da nova xeración, como Xosé Luís Franco Grande, Manuel María ou o seu íntimo amigo Reimundo Patiño (cando este se trasladou a Madrid). Na primeira carta a Franco Grande, escribe («Carta a Franco Grande», 24-8-1957, en Franco Grande 1985: 188):

10 Esta denominación ten como antecedente a etiqueta «Generación de La Noche», proposta por Raimundo García Domínguez, Borobó (Franco Grande 1985: 31). Franco Grande contemplou tamén a pertinencia do nome xeración Illa Nova, dado que varios dos autores debutaron nesa colección de Galaxia.

${ }^{11}$ Este núcleo coruñés, para Méndez Ferrín, «é un grupo cultural que se adscribe á tradición nacionalista (anque non todos os seus membros escriban en galego); axunta unha importante información sobre a literatura anglosaxona, alemana e nórdica (Joyce, Kafka, Lagerkevist, Jocelyn Booke, Brecht) e desdeña explicitamente a lectura do que España consideraba novedosos e firmes valores (CELA, premios Nadal, CELAYA), así como manifesta unha clara refuga por Camus e os novelistas católicos franceses. O núcleo coruñés mantense moi cohesionado arredor da súa peculiar concepción da arte, ata 1957, máis ou menos. Figurarán nel tres narradores: Xohán Casal, José Luis Aranguren e Reimundo Patiño» (Méndez Ferrín 1986: 262-263). 
Yo tengo la misma edad que Vd. y escribo en gallego, pero no conozco a nadie, ni nadie me conoce. (...) He llegado a un punto en el que necesito un cambio de ideas con alguien. Necesito hablar sobre literatura, sobre literatura gallega. Necesito que me den consejos, que me digan si lo que yo hago es bueno o malo.

A correspondencia dispoñible no Fondo Xohán Casal da RAG — composta por unha trintena de documentos, entre cartas recibidas e borradores de cartas enviadas - testemuña sobre a importancia dos intercambios epistolares que mantivo. Nun caso coma o de Casal, a comunicación por carta resultaba fundamental para actualizar perspectivas, intercambiar opinións, madurecer ou contrastar ideas etc., como é natural, e revélase como un vehículo de reflexión e de argumentación crítica para o desenvolvemento da propia estética, como apuntamos máis arriba. Malia o marco sociopolítico do franquismo e do dobre illamento que viviu na Coruña da época - no persoal, debido á súa doenza, e no político, debido ao contexto represivo-, Casal loitou por articular e aplicar unha visión propia da literatura galega, absorbendo ideas e reunindo reflexións. Tratábase, en suma, de quebrar a sensación de frustración e desánimo que padecía e da que se laia repetidamente ao longo da súa correspondencia.

A vontade de Casal por ser escritor galego e por acadar a excelencia nese desempeño plásmase en esforzo e traballo para coñecer o mellor posible a literatura galega e para perfeccionar a ferramenta expresiva da súa elección, a lingua galega. Criado e educado nun ambiente fortemente castelanizado, é consciente de que o seu dominio da lingua podía presentar eivas ou lagoas e proponse formarse para elevar o seu nivel ${ }^{12}$, na procura do perfeccionamento da ferramenta expresiva que conscientemente escolleu. Para isto, bota man dos materiais ao seu alcance na época e céntrase no estudo da Gramática galega de Manuel Lugrís ${ }^{13}$.

\section{III.- EIXOS TRANSVERSAIS NO PENSAMENTO DE CASAL: A FUSIÓN DO RELIXIOSO CO POPULAR}

En conxunto, as súas cartas, diarios e ensaios deseñan o retrato poliédrico de Casal como unha figura situada na periferia, pero aínda así estreitamente conectada ao mundo por lazos intelectuais e amicais: revélase así unha autopoética en movemento, a dun autor que busca, cuestiona e procura unha posición ética e estética no marco do galeguismo. Tamén o debate filosófico e relixioso, na intimidade da reflexión persoal, preside boa parte dos textos, nos que desvela as súas inquedanzas existenciais (na procura da súa definición como home no

12 Por outra banda, mostra interese en cuestións normativas: «Dime (...) o que opinas do libro de Guerra da Cal e a nova ortografía que Piñeiro leva tamén no miolo» («Borrador de carta a Reimundo Patiño», 7-12-1959).

13 «[S]empre me lembro do que di M. Lugrís na súa Gramática do idioma galego, no capiduo de castelanismos: Castelanismo: fogar. Galego: lar. E o "fogar" foise quedando inda máis curto» («Allá en tiempos que fueron», s/d). 
mundo) e a relevancia da práctica da literatura no seu programa vital. Para Casal a creación literaria é a vía para a comunicación e a acción, e afirma:

$\mathrm{Na}$ afirmación «Eu son un home» quérese siñificar que estou entretecido cos demáis homes, que son o mesmo que todos iles... Eu vivo porque estou integrado â humanidade i â vida. Nós somos homes.

Mais isto é dóoroso. É mellor dormir. Pechar os ollos, soñar, facer poesías. («Diario», s/d).

Por veces, ese proceso de formación política e estética, alimentado polas lecturas e o intercambio epistolar e articulado na escrita, pode manifestarse como convulso, doloroso e mesmo contraditorio. A carón de emocións como o pesimismo, abrollan un entusiasmo vital proxectado na literatura e a política, unha vontade de acción e de transcendencia e unha gran espiritualidade, elementos dos que se serve para combater a escuridade e sublimar a dor existencial. Esas emocións positivas son transversais nos textos de Casal, fundamentalmente na correspondencia, ensaios e diarios. En calquera caso, debátese entre a vontade de abrir o seu horizonte e o mantemento dun «equilibrio intelectual», como lle escribe a Patiño («Borrador de carta a Reimundo Patiño», 7-12-1959).

Como se verá a seguir, a relixiosidade, a preocupación pola ética e o compromiso social e político constitúen os eixos fundamentais do posicionamento estético e ideolóxico do autor. Estes elementos están presentes no conxunto da produción casaliana e fanse presentes especialmente nos seus escritos privados (cartas, diarios, ensaios), textos que contribuirán a encadrar o autor no contexto cultural e literario da época.

\section{a) Espiritualidade e relixión: cara a un realismo comprometido e espiritual}

A centralidade da figura de Deus atópase entre os trazos máis relevantes da cosmovisión de Xohán Casal. En efecto, Casal coloca a Deus como centro da experiencia do individuo: para el, realidade e transcendencia relixiosa funcionan como dúas caras da mesma moeda. Así, afirma «[n]o home só hai unha realidade», que sería Deus, para concluír que todo o demais «n[']e mais c'unha caratula mais ou menos tráxica» («Allá en tiempos que fueron», s/d). Por conseguinte, para Casal estas dúas facetas da vivencia humana representan os dous piares da creación literaria, dado que esta só se pode construír sobre a experiencia vital.

No plano biográfico, esta vivencia particular da espiritualidade proxectada na práctica da literatura - en tanto que autor- ábrelle as portas a unha experiencia vital plena ou, cando menos, un posible camiño de acción, unha vía de superación do pesimismo e da angustia que o atormentaron adoito. Así, Casal concibe o funcionamento da literatura coma ferramenta de expresión para proxectar o sentimento relixioso do $\mathrm{eu}$, co que o suxeito logra dar transcendencia ao propio sufrimento («Borrador de carta a Franco Grande», 26-9-1957): 
A door pódese superare sobor si mesma, coma Christo crucificado, por enxempro, pro se a door é pesimista non hai superazón posibre. (...). Pro xa che digo que eu decatárame de ise meu regosto no têbroso - regosto pasivo, negativo, egoísta, pesimista - e andaba a me curare. Xa avantei moito. Eu camiño cara â Alegría, â Paz —é o que ti chamas felicidade— por iso me estrañou unha acusación que me fás: que eu emborco a miña cativa dóor sobor os demáis. Unha cousa é que a miña visión da vida sexa pesimista e outra é que teime facer aos outros copartícipes da miña door. (...) En todo caso eu quero recoller a dóor de todos para cangalo sobre os meus frós. A miña dóor me ten sen coidado. ${ }^{14}$

En carta a Franco Grande, Casal reflexiona sobre o xeito de superar eses sentimentos pesimistas e pensamentos escuros, para concluír enunciando a súa idea de fusión entre a literatura e a fe relixiosa («Borrador de Carta a Franco Grande», 26-9-1957):

Pós unha solución ao probrema: a poesía. Tamén eu coñecía isa solución. A poesía das cousas da vida. ¿Qué outra cousa é o Esprito Santo? Nebrastes das verbas de Christo en Mt $12.32^{15}$ e Mr 3.29 ${ }^{16} ? . .$. isa poesía a levo soterrada... baixo qué? Si, na miña vida a Soedade —o Deserto, o Vougo— gañara moito lugar. Si, eu teño un fondo senso da Poesía das cousas. Se non, ¿por qué vivir? Sinto lazo na i-alma. De todos xeitos xa sabes ti que a poesía de Dios entra pol-o máis pequeño buco... teño de ir â vida —a vida que me desbotou e que me desbota - co corazón aberto.

Na procura da centralidade de Deus na creación literaria, Casal atopa en Eduardo Pondal un referente de excepción. Para el, Pondal é quen de fornecer as liñas mestras polas que a literatura galega podería transitar: a omnipresente idea da divindade (o Deus cristián, para Casal), a espiritualidade panteísta e a acción galeguista. Propugna así seguir como modelo a obra do poeta bergantiñán Pondal, de quen afirma: «O único poeta realista da Galiza foi Pondal, o unico Bardo» («Allá en tiempos que fueron», s/d), ao tempo que reivindica a súa achega no plano lingüístico ${ }^{17}$. Convencido da vixencia de Pondal e da utilidade do seu exemplo, desenvolve esta idea longamente e recrimina aos autores galegos contemporáneos por non seguiren, ao seu entender, os vieiros poéticos abertos polo bergantiñán.

14 Substituímos o subliñado do orixinal manuscrito por letra cursiva. Ao longo deste artigo e salvo aviso do contrario, aplicaremos esta substitución aos subliñados que aparecen nos borradores de cartas manuscritas por Casal.

15 Mateo 12.32 (Novo Testamento): «Deus perdoará incluso a aquel que diga algo contra o Fillo do Home; pero non perdoará a aquel que coas súas palabras ofenda o Espíritu Santo».

16 Marcos 3.29 (Novo Testamento): «A todo aquel que dixer algunha palabra contra o Fillo do Home, seralle perdoada; pero ao que blasfemar contra o Espírito Santo, non lle será perdoado».

17 Afirma Casal: «coido — con toda sinceridade - que a Pondal non se lle fai moito caso, e atá lle corrixen a ortografía e a sintaxis sen se decatar que foi o úneco que teimou de crear unha sintaxis galega» («Borrador de carta a Franco Grande», 26-9-1957). 
É que non se decatan que Pondal calou no mais fondo da realidade e dixo que tiñamos de facer unha lingoa nova, c'unhas ideias novas, c'un novo ideal, c'unha nova forza, c'unha nova auténtica realidade, c'un Deus novo?

Non se decatan co home somentes e universal cando ten calado tan fondo na i-alma da sua terra que incrusive ista tornase humán e vai cobrando nome d'herói? Veñan as realidades da cultura allea que as maquinas feitas por outros afundan a terra, ca cultura allea, non feita por nos, afonda os homes, que a nosa vida esvaiase com’as cinzas do lar antergo. («Allá en tiempos que fueron», s/d)

Sen dúbida, o desenvolvemento dunha literatura relixiosa en Galicia era unha cuestión de importancia capital para Casal, como revela na súa correspondencia: «¿qué pensas da poesía propunada por Pondal? ¿Coidas n’unha literatura Relixiosa en Galicia?» («Borrador de carta a Franco Grande», 26-9-1957).

Pondal tamén está na base da súa reivindicación dunha espiritualidade panteísta, para o que se apoia na conexión das ideas de «pobo»e «raza», entendendo esta como «cultura» en estreita vinculación co telúrico: «Raza para min é xustamente Cultura. Raza-Home-Cultura van xunguidos. O Telúrico e a Raza teñen un senso moi proisimo na miña «nomenclatura» («Borrador de carta a Franco Grande», 26-9-1957).

Na cosmovisión de Casal, realidade e espiritualidade panteísta fúndense na idea de pobo galego, na existencia efectiva e real da xentes persoas do pobo, de xeito indisoluble: a través da fe, que permite a sublimación do espírito e a transcendencia relixiosa das cousas, integraríanse os dous planos, realidade e espiritualidade. A fusión do divino (Deus) e o pobo, a través da «raza», maniféstase nesta pasaxe, por exemplo:

A raza vai tendo con Deus un contaito estranamente aterrecedor, vai coñecendo a Deus... vaise facendo unha «ideia» de Deus. Tamén faise unha ideia da Morte, e do Amor e tamén — dendo caborco onde s'acuruxan Deus, Morte, Amor e Raza - vai facéndose unha ideia da Natureza... E de súpeto xurde ista afirmación: A Natureza é a Eternidade. O galego vive sulagado na corrente infinda da sua raza e dende ela olla â Natureza. Dende máis aló da Morte. Dende máis aló do Alén olla â Natureza. Ollaa cheo d'un infindo terror tremelucente. Unha terribre Natureza alóngase à o cinguir; está inzada de medos e segredos indescifrables. Zicáis o exconxuro poderá contela, o exconxuro pode redimir de moitas escuridades.

Pro a forma máxica xurdiu do subconscente do home, i é unha pura atraición ondia a pantesía pecha a sua arela de comunicación con Deus. O símbolo relixioso xurde cheo de siñificado. O seu siñificado é «universalmente válido». («No Courel. Tipos de S.A. de Teixido», s/d)

Como se ve, Casal propugna seguir o ronsel pondaliano, que na súa lectura implica facer propia a vinculación Terra-Raza-Natureza/Nai-Deus, reivindicando así mesmo a lingua como elemento identitario: 
Falare galego.

Vivire galego.

Pensare galego.

E... finar coma galegos, cheos de Deus. Non hai outro anceio pra o home.

Que se non podedes atopar no voso peito a verdade dos heroes, do lar, do clan, a verdade vidal d'os homes... mais vale que vos vallades a caron da Natureza, denantes ca cultura a faga cachizas, e esperedes coa vosa carga o xuicio de Deus. («Allá en tiempos que fueron», s/d).

Afondando nesa liña, Casal apela a cambiar a perspectiva e poñer en valor os valores propios, a cultura e a terra, cunha perspectiva popular, realista e comprometida coa espiritualidade, sen mimetismos alleos nin idealizacións falseadoras. Por iso exhorta os escritores coetáneos a que recuperen a Pondal como referencia fundamental («Allá en tiempos que fueron», s/d):

Eu vos prego que non querades as formas d'outros, o modo alleo de vivire, que traballedes na vosa lingoa coma quen traballa co lume sagrado, que cada verba sexa solemne e forte, coma d'un prego. Coma se falasedes con Deus.

Non vos decatades que a solemnidade de Pondal n[']e outra cousa? Non vos decatades que o seu mundo «irreal» e o mundo do home que fala con seu Deus?

Casal refuga nestes textos tanto a estranxeirización como a falta de autenticidade, e propugna unha renovación desde unha clave interior, desde a propia especificidade, para lograr transcendencia. Fronte ao folclorismo ou á emulación de tendencias estranxeiras que percibe na narrativa de comezos dos cincuenta $^{18}$, Casal propón un camiño de fidelidade ao pobo, de fe e de compromiso, incorporando «a visión profética $e$ terribremente relixiosa» de Advento de Manuel María (1956) aos «obreiros retrincados» de Fardel de eisiliado de Luís Seoane (1952) («Borrador de carta a Reimundo Patiño», 27-9-1958, en Bermúdez 2011: 176-179). Nesa mesma liña, Casal recorre de novo a Pondal para insistir na importancia de pór en valor o propio e non emular autores estranxeiros, nun alegato dirixido implicitamente aos seus contemporáneos e, en especial, aos novos escritores galegos («Allá en tiempos que fueron», s/d):

Se encetades perdoando a vida aos homes que fixeron posíbel vosa vida, somentes porque iles non tiñan cultura, ou non eran científicos, e inda engadides, tiñan moito entusiasmo, mais outra cousa non! Iles eran galegos e iso é todo.

D'aquela inda había lar. E acarón do lume facíase unha rolda d'homes verdadeiros. Oxe nos cafés ou nos estudios, fártanse de ler e de falar, e logo viven ao seu xeito pol-as ruas adiante e... copian a Kafka ao escribire, poño por caso. Será qu'inda non atoparon coa unica realidade que anunciou Pondal? Será que é mais importante oxe traducir do frances e ingles un feixe de poesías ou un libriño de filosofía aleman que poñer en galego o Éxodo ou a Biblia enteira?

18 «A novela d'oxe ou é calcada da estranxeira ou é folklorica. Ou o mariñeiro e a vaquiña e a rapaciña ou a cultura inglesa» («Allá en tiempos que fueron», s/d). 
Ademais, Casal insiste de xeito repetido na procura da verdade en Deus, na busca do elemento espiritual e emocional da vivencia do ser humano, aquela que daría lugar á transcendencia, fronte ao desvirtuamento desa experiencia («Allá en tiempos que fueron», s/d):

A realidade do home é Deus. Digan o que digan os profundadores da «esteitica».

E a brutalidade da vida, a fame, a trincheira, e a reproducción son si, cousas moi importantes cando no miolo vai unha realidade vidal enfiada até Deus, mais cando o home arredase n'istas realidades, xa non hai n'in (sic) a mais cativa realidade n'il. Xa non hai ren.

Xa que logo, trataríase de buscar a autenticidade na propia realidade, unha realidade que funde o elemento popular cunha espiritualidade telúrica e que abre o único camiño cara á universalidade. Por isto destaca Casal en Eduardo Pondal e Rosalía de Castro a proximidade coa terra, grazas ás súas infancias no ámbito rural: «Os poetas que coma Rosalía e Pondal viviron perto da campía poideron cantar primeiramente o seu mundo de terra e logo o verdadeiro mundo de todol-os homes» («Allá en tiempos que fueron», s/d) ${ }^{19}$. Casal presenta a natureza como un espacio aberto e un escenario da liberdade, un espazo soñado que se contrapón ao hábitat urbano que conformaba a súa experiencia cotiá ${ }^{20}$ («Carta a Manuel María», 27- 7-1958, en Casal 2005: 217-230):

Soitario na vila, antre 200.000 habitantes, n'iste domingo ledo de sol e triste de homes — que desánganse no asfalto— sinto a arela de voltar ao âr ceibe da miña aldeia (isa aldeia que nunca tiven, nin no relembro) e ao non poder síntome n'unha gaiola sen buco. Ás vegadas sono con que ando pola herba ao âr, e o meu sono é unha tortura. Nebro unha pelícola na que un home caía dentro d'un broque de cemento e alí ficaba.

\section{b) O popular e o relixioso nunha Galicia en transformación}

Os anos cincuenta do século XX foron escenario dunha radical transformación demográfica, económica e cultural en Galicia, materializada nunha intensa migración do campo para a cidade. Núcleos urbanos como A Coruña e Vigo, así como o resto das cidades e vilas galegas, absorberon un fluxo de

19 Noutra pasaxe, afirma: «Eu vos prego que choedes as portas, xa que inda estamos a tempo. ¿Queredes unha filosofía? Facédea. ¿Queredes unha literatura? Facédea. Non vos digo que non olledes, cos ollos da carne ben abertos coma fan os outros. Agora vos prego que a "nosa" cultura a fagades dende a nosa mesma terra. Que xurda d'ila coma un albre, que xurda da i-alma do pobo. Que si sodes verdadeiros xa vendrá a universalidade» («Allá en tiempos que fueron», s/d).

20 Non obstante, nunha cidade do tamaño da Coruña da época (147.00 habitantes, aproximadamente), o contacto co rural era fluído: Casal movíase adoito polas áreas aínda rurais como Eirís ou Elviña, por zonas veciñas como os castros de Vilaboa (Culleredo), Fonteculler, Santa Cristina, San Pedro de Visma, San Roque ou O Portiño. Tamén pasou tempadas en Vilanova de San Pedro (no verán de 1955), por exemplo. 
persoas provenientes do rural que se viron obrigadas a desenvolverse e adaptarse nunha contorna descoñecida e, por veces, hostil, tanto en termos sociais como lingüísticos.

Neste sentido, Casal manifestou unha fina percepción desa profunda transformación socioeconómica e cultural que sacudía a Galicia da súa época, coa masiva migración rural-urbano e a «desculturación» que isto provoca nas persoas migrantes, como se percibe tamén no relato «A soidade» (Casal 2005: 135136), protagonizado por un cura aldeán que chega a un arrabalde en proceso de urbanización ${ }^{21}$. Con perspectiva crítica, Casal alertaba sobre os cambios de costumes $^{22} \mathrm{e}$ valores, de mentalidade e de usos lingüísticos que o éxodo ruralurbano estaba xa producindo na sociedade daquela época, ao tempo que avisaba do risco de inautencidade para a literatura galega que podía levar aparellado.

Por iso, Casal refugou unha visión idílica e estetizante, intelectualizada e atemporal da Galicia - isto é, aquela caracterizada pola presenza de esencias inmutables e cultivada desde a órbita piñeirista - por considerala unha imaxe desconectada da realidade presente e, polo tanto, carente de autenticidade, en ocasións «folclórica» e en todo caso «sen raíces na gleba» (Casal, en Patiño 1985: 146). En contraposición a isto, a proposta de Casal reivindicou unha representación alternativa, que incorporase a observación da realidade en transformación, a dunha Galicia en transición cara ao urbano, sen excluír da representación os novos perfís da clase traballadora: «¿Onde fican os galegos das cidades? ¿Quen os ollóu nunha obra verdadeiramente galega? (...) ¿Cavilou alguén nos sofrimentos distes homes alonxados da Natureza e espetados na vila? (...) ¿Se un perde a Natureza (...) non perderá tamén a Deus, ó Amor e até a mesma Morte?» (Casal, en Patiño 1985: 146). Da vontade de integrar eses galegos, por unha banda, e de facer unha literatura valiosa e auténtica, por outra, naceu o posicionamento de Casal: «Ises homes que aínda falan en galego, que cas verbas que Fole adica ó Caurel fan a Galiza descoñecida, perdida, asulagada, teñen dereito ó seu Deus perdido. O novelista ten de devolverllo» (Casal, en Patiño 1985: 147; cursiva nosa). Ao longo dos seus escritos, Casal mostrou en diversas ocasións a súa empatía cos traballadores: «Eu pra min teño a vida que decorre polas rúas "aínda galegas" da vila - Gaiteira, Castros, Pedra Longa, etc. (...) [E]u che ando polos peiraos cos homes chegados do mar, ou cos obreiros» («Carta de Xohán Casal a Xosé Luís Franco Grande», s/d, en Casal 2005: 212-216).

En definitiva, como consecuencia derivada desta versión de realismo, Casal adiantouse na reividicación activa dunha cidade humanizada como espazo ficcionable e compatible coa galeguidade, como plasma en varios dos seus relatos.

${ }^{21}$ «Labrego coma o seu pai, il non fuxía do sacho, il sentía na súa i-alma unha forza irresistibre que o levaba a Deus. (...) A súa parroquia ficaba nas abas, no máis alonxado da vila, perto do campo, lonxe do campo. Entrou nela coma un extranxeiro. O seu aspecto de labrego chamou a atención. Os seus andares e as súas falas. (...) Chorou a cheo de desespero» (Casal 2005: 135-136).

22 «Agora coa cultura, señores, a lareira está de mais, iso e cousa de bárbaros, agora veñe a cociñilla electrica, e tamén veñe o desprecio pol-a verdade do home, pol-o seu sofrimento» («Allá en tiempos que fueron», s/d). 
Abriu así a «posibilidade de crear unha narrativa que sexa puramente galega desde a cidade», como confirma Regueira (2020: 289).

A toma de conciencia á que Casal apelou vincula a espiritualidade e a realidade nunha vindicación da propia cultura, desde o convencemento de que sería esta cultura o elemento capaz de transcender cara á universalidade ( Borrador de carta a Franco Grande», 26-9-1957):

O home internacional é un conto. Ti relée as cen cantigas populares arrecadadas por Noriega, ou olla os monequiños de San Andrés de Teixido e di logo que non hai raza. (...). Ti podes ser moi home ceibe, podes ter moita cultura —calqueira home d'após o renacemento é asín — pro âs vegadas terás que che voltar cara â tua paisaxe, â tua terra, â tua tradizón, ao teu pobo para zugar deles o sangue que galga nas tuas veas. Noso deber é camiñar con total sinceridade - polo camiño da vida e do sentimento - cara ao ponto onde se xunguen terra-home, ondia sorte o latexar da nosa vida peculiar, ondia está o alicerce da nosa total orixinalidade, ondia cos ollos para dentro de nós, fitamol-o arfar das vagas que veñen do remoto da Terra e do Tempo traendo un mensaxe. Algo que nutre a todos por igual. ¿Qué outra cousa é a comunicazón silandeira dos espritos?

De xeito persistente, como vemos, Casal exhortou os seus coetáneos a cambiar de perspectiva e a actualizar os valores propios, a cultura e a terra, cunha base popular, realista e comprometida coa espiritualidade, sen mimetismos alleos nin idealizacións falseadoras. Nesa liña, e como xa se apuntou máis arri$\mathrm{ba}$, animaba os escritores a recuperar a Pondal como referencia fundamental («Allá en tiempos que fueron», s/d):

Eu vos prego que non querades as formas d'outros, o modo alleo de vivire, que traballedes na vosa lingoa coma quen traballa co lume sagrado, que cada verba sexa solemne e forte, coma d'un prego. Coma se falasedes con Deus.

Non vos decatades que a solemnidade de Pondal n[']e outra cousa? Non vos decatades que o seu mundo «irreal» e o mundo do home que fala con seu Deus?

Así, a práctica da escrita proporcionaría a ocasión de servir á Terra e a Deus, transcendendo do individual ao colectivo: «Temos de salvar a i-alma cos nosos esforzos, cos nosos ollos, coa nosa terra, coas nosas pedras, Noso Deus nos fará xuicio según noxas leixes» («Allá en tiempos que fueron», s/d). Para isto, é preciso empregar unha linguaxe poética limpa e sen artificios (en contraposición a Cunqueiro ${ }^{23}$ ), capaz de revelar a autenticidade que provén da «sinceridade relixiosa». Casal propugnará un estilo «ríspido», en aras da «sinceridade máisima», isto é: «A sinceridade Relixiosa, e ti xa sabes que a poesía é a música do corazón, e notare na outura das ideias, no pran da obra, no ritmo, máis

23 «A narración debe de ser direita e sen figuras poéticas. A poesía debe de xurdir coma un arrecendor.. Toda isa enxurrada de verbas: "estrelecer, solpor, donas do corpo delgado, etc.", as deixo para Cunqueiro que ten moito que acochar» («Borrador de carta a Franco Grande», 26-9-1957). 
que nas verbas enfiadas aló ondia se fala de tudo aquello (sic) que débese “notar"» («Borrador de carta a Franco Grande», 26-9-1957).

Patiño foi o primeiro en poñer de manifesto o peso do «senso relixioso» de Casal, situándoo «a cabalo antre o cristianismo postconciliar — anos denantes de Xohan XXIII- mesturado ca creencia panteista dos nosos devanceiros na pervivencia alén da morte na propia terra a través do amor» (Patiño 1985: 141). Efectivamente, atopamos adoito nos textos de Casal un espírito evanxélico acompañado de certo franciscanismo, relacionado coa relixiosidade popular á que xa nos referimos. Son protagonistas dos seus contos e poemas os excluídos, os marxinados, os desarraigados, os que fracasan ou morren, en definitiva, as vítimas, ás que se lles concede unha posición de centralidade nos textos. Bota man así de personaxes como o sapo, a araña ou o can, que simbolizan a exclusión da sociedade e a través dos que se transmite empatía cos inadaptados, como acontece en «O falar dun sapo» ${ }^{24}$, «A visita» (Casal 2005: 111-112) ou «A soidade», por exemplo.

Como se ve, a relixiosidade -indisociable da tradición popular, do telúrico e dunha idea de «raza» entendida como cultura- é absolutamente central na perspectiva de Casal. Cómpre salientar tamén que a impronta da lectura da poesía de Pondal no ideario estético de Casal é fundamental, xunto coa obra de Manuel María e Luís Seoane («Borrador de carta a Patiño», 27-9-1958, en Bermúdez 2011: 176-179).

Por outra banda, esta relixiosidade casaliana afastábase das orientacións do catolicismo oficial, practicado pola Igrexa española e imposto pola ditadura nacional-católica ${ }^{25}$. Pola contra, a relixiosidade de Casal compúñase de

${ }^{24}$ Neste conto, a voz narrativa é a dun sapo, caracterizado como ser soterrado na escuridade e esmagado pola soidade, a angustia e a incapacidade de expresar a súa emoción (o amor por todos os seres) ao mundo. O personaxe simboliza a inadaptación e a soidade e resulta ben recoñecible como trasunto do propio Casal: «Por estar só, eu quixera falarvos do amor

Quixera falarvos dil — a vós os desenganados pola vida — dado que tamén eu son un desenganado.

(...) ¿Quen rescibiu niste mundo inmenso, povoado de seres vivintes o meu amor aceso? ¿Quen ouviu tan siquer — antro balbordo aturante dos sapos- a miña voz?» (Casal 2005: 148).

${ }_{25}$ Casal pediu consello espiritual en cartas a sacerdotes da Coruña como José Luís Blanco (93-1957) ou até de Madrid, como o padre Venancio Marcos, a través da Radio Nacional de España (9-3-1957). Estas diferenzas dan lugar a un debate epistolar no que o padre Marcos lle reprocha a Casal estar afastado da igrexa: «Pero aun en el caso de que viva Vd. en una perenne tensión espiritual, vive alejado de Nuestra Iglesia. Esta es la verdad.

No se sirve a Cristo a gritos y con ademanes, se le sirve en la sonrisa y en el sueño, en el amanecer y en el alma. A Cristo se le sirve en la renuncia de la personalidad — no se escandalicemundana. Hay que hacer morir al hombre viejo. Si no se muere, no se resucita, si no se resucita ¿qué hacemos aquí? Hay dos personalidades. La de este mundo y la que no es de este mundo. La que actua ("nordicamente", para usar esa nomenclatura suya tan particular) por si sola, independiente, soberbia, libre - "cuando me constriño, soy libre. Cuando me creo libre, me constriño" ¿Goethe? - y la humilde, la que se somete, la que hace Su Voluntad — la voluntad de Dios — cada día, cada minuto piensa en lo que le será agradable, a Dios y al prójimo» («Supuesta respuesta del Padre Marcos a Juan Ignacio Casal», s/d).

Segundo precisa o sacerdote en nota a rodapé, «Mundano para mí es Kierkegaard en su autoafirmación» (cursiva nosa), elemento co que o relixioso non concordaba. En definitiva, as posicións de Casal e da igrexa española estaban claramente contrapostas. 
profundas inquietudes espirituais, de preguntas sen resposta, de angustia e ansia de transcendencia. A súa relixiosidade era crítica, cuestionadora, reflexiva, singular. Podemos situar a posición de Casal na órbita do existencialismo teísta de Søren Kierkegaard (1813-1855), que abrira a posibilidade da transcendencia da vida desde unha óptica cristiá.

\section{A MODO DE CONCLUSIÓN E PECHE}

Como vimos, nos seus escritos (cartas, diarios, ensaios), Xohán Casal reflectiu o seu pensamento particular, comprometido e crítico, en relación con Galicia, coa escrita e co mundo, o que nos permite estudar a conformación do seu universo intelectual e caracterizar a súa figura.

Grazas á análise destes textos, na súa maioría inéditos, tentamos descubrir as claves mestras do pensamento de Casal, no que distinguimos dúas liñas interrelacionadas: a da espiritualidade e a relixión, por unha banda, e a focalizada no popular, por outra. Inspirado na súa lectura de Eduardo Pondal, para Casal a relixiosidade é indisociable do telúrico e do popular: a vivencia da espiritualidade vén do pobo e conduce á comuñón con el, de xeito que concibe unha idea de pobo ineludiblemente marcada pola súa conexión coa divindade. O panteísmo, por un lado, e a preocupación pola vida tras a morte, por outro, son elementos omnipresentes no seus escritos, tanto literarios como persoais.

Esta relixiosidade maniféstase na súa obra en conxunción coa vontade de contribuír ao proxecto galeguista por medio da escrita literaria. En relación con isto, a identificación dun triplo eixo formado polo impulso espiritual, o compromiso popular e a acción galeguista permítenos entender o desafío rotundo que representou a actividade de Casal á imposición franquista do modelo de homo patiens (Cayuela). Do estudo dos seus escritos podemos concluír que esa vivencia particular da relixión supuxo un impulso para a súa actividade creativa e contribuíu a motivar a súa rebelión contra o modelo de cidadán submiso ao réxime. A pesar das dificultades, da frustración e do desespero pola hostilidade do ambiente, Casal mantívose firme na súa decisión de desenvolverse como escritor galego, desde a consciencia da súa particularidade.

Por outra banda, cabe destacar como achega fundamental de Casal á narrativa galega a súa proposta dunha nova imaxe da Galicia: trátase dunha imaxe en concordancia co seu tempo e coa realidade popular da sociedade dos anos cincuenta, en plena transformación urbana e periurbana, aquela que non era reflectida polos autores do círculo de Galaxia. Casal foi quen de percibir e representar literariamente a convulsión demográfica e as transformacións socioeconómicas que sacudían unha Galicia silenciada e en tránsito.

\section{BIBLIOGRAFÍA}

Arquivo da Real Academia Galega, Fondo Xohán Casal, A Coruña, Real Academia Galega. 
Avilés de Taramancos, A. (1992) Obra Viva, Laiovento, Santiago de Compostela.

Bermúdez Montes, M.T. (2005) «Estudo introdutorio», en Casal, X. O camiño de abaixo. Vigo, Xerais, pp. 7-105.

Bermúdez Montes, M.T. (2011) «Palabras na penumbra. Un achegamento á ideoloxía e á estética de Xohán Casal», Revista de lenguas y literaturas catalana, gallega y vasca (Anuario de filología catalana, gallega y vasca), XVI. Madrid, UNED, pp. 163-182.

Casal, X. (2005) O camiño de abaixo, Vigo, Xerais.

Cayuela Sánchez, S. (2009) «El nacimiento de la biopolítica franquista. La invención del "homo patiens"». Isegoría, 40, pp. 273-288, june 2009. Dispoñible en: http://dx.doi.org/10.3989/isegoria.2009.i40.660 (marzo 2020).

Cayuela Sánchez, S. (2014) Por la grandeza de la patria. La biopolítica en la España de Franco (1939-1975), Madrid, Fondo de Cultura Económica de España.

Franco Grande, X.L. (1985) Os anos escuros, I. A resistencia cultural da xeración da noite (1954-1960), Vigo, Xerais.

Martínez Cavero, P. (2015) «CAYUELA SÁNCHEZ, Salvador: Por la grandeza de la patria. La biopolítica en la España de Franco (1939-1975). Madrid: Fondo de Cultura económica», Revista Murciana de Antropología, 22, pp. 305-308. Dispoñible en: https://revistas.um.es/rmu/article/view/241781 (maio 2020).

Méndez Ferrín, X.L. (1986) De Pondal a Novoneyra, Vigo, Xerais.

Molina Aparicio, F. (2017) «La reconstrucción de la nación». Homogeneización cultural y nacionalización de masas en la España franquista (1936-1959)». Historia y Política, 38, pp. 23-56, november 2017. Dispoñible en: https:// doi.org/10.18042/hp.38.02 (maio 2020).

Patiño Mancebo, R. (1985 [1970]) «Prólogo», en Casal, X. O camiño de abaixo, Sada-A Coruña, Ediciós do Castro, pp. 11-19.

Patiño Mancebo, R. (1985) «Epílogo á segunda edición. Escritos no tempo polo que levo viaxado nestes meses», en Casal, X. O camiño de abaixo. Sada-A Coruña: Ediciós do Castro, pp. 137-152.

Prieto, A. (1985) "Xohán Casal, escritor coruñés muerto en 1960 a los 23 años, será objeto de un homenaje en enero". La Voz de Galicia, domingo, 3 de noviembre de 1985, p. 29.

Ramírez-Melgarejo, A.J. (2014) «Salvador Cayuela Sánchez. Por la grandeza de la patria. La biopolítica en la España de Franco», Sociología histórica 4/2014, pp. 551-559. Dispoñible en: https://revistas.um.es/sh/article/ view/215681 (abril 2020)

Regueira, M. (2020) Narrativa e imaxinario nacional na reconstrución do campo literario de posguerra (1936-1966), Vigo, Xerais. 
Rivas, M. (2009) A boca da literatura. Memoria, ecoloxía, lingua. Discurso de ingreso na Real Academia Galega lido o 12-12-2009 na Coruña, A Coruña, RAG.

Scott, J.C. (1990) Los dominados y el arte de la resistencia, Nafarroa, Txalaparta. 